Revista de la red interuniversitaria de estudios sobre las literaturas rioplatenses contemporáneas en Francia

$10 \mid 2014$

El XIX en el XX

\title{
Los tiempos de Lucio V. Mansilla
}

\section{Sandra Contreras}

\section{OpenEdition}

\section{Journals}

\section{Edición electrónica}

URL: http://journals.openedition.org/lirico/1710

DOI: $10.4000 /$ lirico. 1710

ISSN: 2262-8339

Editor

Réseau interuniversitaire d'étude des littératures contemporaines du Río de la Plata

\section{Referencia electrónica}

Sandra Contreras, «Los tiempos de Lucio V. Mansilla », Cuadernos LIRICO [En línea], 10 | 2014,

Publicado el 15 marzo 2014, consultado el 10 diciembre 2020. URL : http://journals.openedition.org/ lirico/1710 ; DOI : https://doi.org/10.4000/lirico.1710

Este documento fue generado automáticamente el 10 diciembre 2020.

\section{(c) (i) (9)}

Cuadernos LIRICO está distribuido bajo una Licencia Creative Commons Atribución-NoComercialSinDerivar 4.0 Internacional. 


\title{
Los tiempos de Lucio V. Mansilla
}

\author{
Sandra Contreras
}

1 En noviembre de 2011 aparece en Buenos Aires una revista llamada Mancilla, con “c”. El subtítulo, muy pequeño, que desaparecerá luego en los siguientes números, decía "La época". Mancilla. La época. Por cierto, la fórmula tenía méritos para llamar la atención con un par de guiños que parecían querer decirnos algo : el cambio de la "s" por la "c", como reproduciendo y transformando la operación que el mismo Mansilla había realizado con otro par de sibilantes (la "z" por la "s" en el apellido de Rozas en el estudio que escribió hacia 1898), pero también la asociación del nombre de Mansilla con el concepto de la “época”, esto es, la conversión de Mansilla en santo y seña de un tiempo que, a diez años del crítico 2001, no podía estar señalando sino, evidentemente, la primera década del siglo XXI. La dirigen, o la "hacen", como lo declaran en su editorial, un colectivo de jóvenes integrado, entre otros, por Juan Laxagueborde, Nicolás Maidana, Florencia Minici . Cada número cierra con un epílogo dedicado a la obra de Lucio V., y abre con un dossier dedicado a una ciudad/zona del país (hasta ahora Bahía Blanca, Neuquén, Mar del Plata, Delta del Paraná, Cuenca del Riachuelo), a excepción del primero, que lleva por título “Textos y texturas del kirchnerismo". ${ }^{1}$ Con lo cual queda claro, de entrada, que es el kirchnerismo, pensado "no desde la razón gubernamental sino como nombre que tiñe la época en su conjunto y revitaliza constantemente nuestras interpretaciones"2, el primer territorio, nacional, que estos jóvenes eligen como propio : la época kirchnerista como un territorio que es una atmósfera y un tiempo político en el que reconocerse como un país y como un proyecto. No me ocuparé, aquí, de la revista. Solo me interesa llamar la atención sobre la pregunta que la convocatoria de su título parece habilitar : ¿qué significa o qué puede seguir significando el nombre de Mansilla hoy? Si los jóvenes vanguardistas de los años 20 identificaron su intervención cultural bajo la advocación de Martín Fierro, ¿cuál puede ser la vigencia de Mansilla para unos jóvenes de filiación kirchnerista, lo que, según los términos en que lo formulan, quiere decir jóvenes con pasión por pensar el "conglomerado de tensiones irresueltas"3 que se abrió con el proceso post-2001 y, sobre todo, a partir del 2003 ? No se trata, por supuesto, de identificar, ni siquiera de comparar, un movimiento de vanguardia estética con una intervención como ésta que, más específicamente, tiene como objetivo "poder problematizar la atmósfera cultural y social argentina desde lo que emerge como novedad o desde lo que está en el pasado para hacer 
estallar los lenguajes del presente: los libros, las palabras, las imágenes, los lenguajes críticos". . No deja de ser interesante, sin embargo, la resignificación política del gesto : convocar e intervenir el nombre de Mansilla para pensar el presente político, social, cultural. Más aún; si se tiene en cuenta que también en noviembre de 2011 se creó el Instituto Nacional de Revisionismo Histórico Argentino e Iberoamericano "Manuel Dorrego" que, bajo la dirección de Mario Ernesto (Pacho) O'Donnel, tiene como uno de sus próceres estrella a Juan Manuel de Rosas, podría pensarse la aparición de la revista no solo como una intervención propia del clima de fiesta de las elecciones de octubre de 2011, que ratificaron de modo contundente el segundo mandato de Cristina Fernández y tercero en el ciclo de los Kirchner, sino también, tal vez, como un retorno del apellido familiar favorecido por un generalizado ánimo nacionalista que, en el marco de los festejos por el Bicentenario, decretó por ejemplo como Día de la Soberanía Nacional al 20 de noviembre, que tuvo al padre de Lucio V. como héroe de la Vuelta de Obligado ${ }^{5}$. No sería justo, sin embargo, atribuirle a este colectivo de jóvenes una ascendencia de estirpe revisionista y nacionalista, cuando el suyo es, claramente en otra dirección, un espíritu atento a las heterogeneidades culturales como el que inspira, en todo caso, al colectivo de Carta Abierta. ${ }^{6}$ El epílogo de María Pía López, que cierra el primer número, funciona de algún modo como manifiesto : el Mansilla que vuelve con los jóvenes kirchneristas es el Mansilla de la Excursión, el de la frontera entendida como un territorio que, ni firme ni nítido, es explícitamente "impuro", "reclama perseguir y capturar las diferencias que allí refulgen" y requiere por lo tanto de "una epistemología del matiz. "Hay matices", decía Viñas. Se va viendo así lo que indica, y suple, esa "c" : se trataría menos de "mancillar" a Mansilla, en el sentido etimológico del término (la fama, tópico mansilleano si los hay), que de trabajar con las manchas, las heridas, las "mancillas", que revela ese nombre en torno del cual podrían reunirse, como "un conglomerado de tensiones irresueltas", los matices de la Argentina del presente.

2 Seguramente, nada le hubiera gustado más a Mansilla que ver asociado su nombre con la posibilidad de interpretar una "época". La conexión con la época, no en el sentido de la urgente intervención política tan propia de los escritores del XIX sino en el sentido del establecimiento de un vínculo con un tiempo de larga duración, con el tiempo amplio en que se despliega una civilización a ser interpretada en el futuro, fue una aspiración que el propio Mansilla tuvo para con su obra. Dice, por ejemplo, en una de sus más célebres causeries :

...Si a la sociedad de ahora no la describimos con pelos y señales, los que quieran saber, dentro de dos mil años, cómo vivía un argentino en el año de gracia de 1889, o durante la guerra de Paraguay, o en los tiempos de violín y violón, no hallarán un solo documento auténtico que se lo diga, y todas serán conjeturas e interpretaciones. Por eso el padre, el fundador, el primero de los autores naturalistas modernos, el inimitable, el incomparable, el estupendo Balzac, ha hecho un verdadero monumento arqueológico, escribiendo su Comedie Humaine. No ; describir los usos, las costumbres, las rarezas, hasta los sarcasmos de una civilización (esta palabra es muy elástica), para explicarse su vida, nunca será un acto ocioso. ${ }^{8}$

3 Y no es otro el núcleo que sostiene medularmente las Causeries: la ambición de lograr, como el "genial y admirable Balzac", una gran obra que, a la vez que compendie su filosofía práctica, describa y haga vislumbrar los usos, las costumbres, las rarezas, las tendencias, de su época. Enfocada desde este ideal balzaciano -que Mansilla enuncia como poética personal cada vez que puede- los volúmenes de Entre-nos pueden ser leídos como la vasta obra de un escritor que se pensó como un arqueólogo anticipado de la Argentina 
del siglo XIX. Claro que, resultado de las anécdotas, relatos y experiencias, que él mismo protagoniza o atestigua, la Argentina documentada del causeur-cronista se extiende hasta coincidir, "elástica", con la "civilización Mansilla". Y es precisamente porque aunó mejor que nadie esa documentación a su propio mito personal, que Mansilla bien podría considerarse el primer escritor de ficción, en el sentido en que hoy hablamos de ficción, de la literatura argentina del XIX. Por esto, tal vez, sea nuestro más estricto contemporáneo.

4 Pero si en este sentido Mansilla merece considerarse un escritor más propio del siglo XX que del XIX, es preciso decir que es un escritor de un siglo XX muy tardío, que no fueron sino la crítica y la literatura del último cuarto del siglo las que, recién, lo convirtieron en nuestro contemporáneo, esto es, en precursor de algunas de nuestras prácticas y sobreentendidos. Si uno de los errores fundacionales de Ricardo Rojas fue el de consolidar hacia los años veinte la idea de que la fascinación que producía el personaje de Mansilla no había alcanzado para cimentar, por su inconstancia e inestabilidad, una obra literaria madura ni, por consiguiente, al "gran escritor que hubiera podido ser", es cierto también que ni el reconocimiento, local e internacional, que le aseguró de entrada a la Excursión un lugar indiscutido en el canon de la literatura argentina del siglo XIX, ni la celebridad que detentó temprana y constantemente como "hombre de letras", fueron suficientes como para que esa condición de "escritor en suspenso" que le atribuía la primera Historia de la literatura argentina no se mantuviera firme, por lo demás durante largo tiempo. ${ }^{9}$ Todavía en 1964 David Viñas seguiría registrando, como Ezequiel Martínez Estrada en 1946, que, convertido en libro de entretenimiento, la Excursión necesitaba aún de una lectura que le hiciera justicia. ${ }^{10}$

5 Con todo, la indiferencia más notable, y por cierto la más interesante, de la que fue objeto Mansilla a lo largo del siglo XX es, claramente, la de Borges. Puede subrayarse, desde luego, ese conocido pasaje en el que, trazando una genealogía para el idioma de los argentinos, Borges le atribuye a las obras fundadoras de Echeverría, Sarmiento, Fidel López, Wilde y Mansilla, el valor singularísimo de una escritura cuyo tono "fue el de su voz"11. Pero esta mención, que si no me equivoco es la única, no bastaría para decir -como sostiene Ivonne Bordelois- que las Causeries imantarán la atención de Borges entre el corpus de obras del ochenta. ${ }^{12}$ El modelo de "prosa de sobremesa, prosa conversada" como ideal de una prosa sin superstición de estilo -al que bien podrían responder los tomos de Entre Nos- es, para el Borges de los años 30, Cervantes, y no Mansilla. Nunca tuvo el causeur, en este sentido, la fuerza de un precursor en la poética borgiana del ideal de la voz. Tampoco la tuvo el coronel, que fue Jefe de fronteras como su abuelo el coronel Francisco Borges, y que por esos mismos años, entre 1870 y 1872, también testimonió, como su abuela inglesa, la historia de una cautiva que, ya casi olvidada de la civilización, rechazó la posibilidad de volver. ${ }^{13}$ Es casi imposible que Borges, siempre atento a la proyección de los pormenores circunstanciales, desconociera estas coincidencias. Al mismo tiempo que es evidente que materiales, tanto anecdóticos como formales, había suficientes en la obra de Mansilla como para merecer su atención. Motivos para la indiferencia, sin embargo, tampoco faltaron. Si la relación familiar con Rosas seguramente no debió haber sido uno de los menores, la incompatibilidad del estilo y del mundo imaginario de Mansilla con la poética y la política borgianas fue, en rigor, el de mayor peso : ni la opción por las formas menores, que en Mansilla se traduce en opción por la literatura ligera pero también en debilidad por la digresión, podía cuajar en una poética sintética del relato, ni la opción por la barbarie de la cautiva inglesa, que en 
Borges funciona como puro desafío y por lo tanto como una de las tantas variantes de la épica del individuo contra el Estado, podía filiarse en el estilo tan directo como melancólico con que el cronista atestigua la historia de Fermina Zárate mientras emprende el regreso de su viaje a los ranqueles. ${ }^{14}$ Todos estos señalamientos, sin embargo, no tienen otro propósito que el de llamar la atención sobre el hecho paradójico de que haya sido justamente Borges quien no vio en el escritor más moderno del siglo XIX ni siquiera al precursor de la boutade con la erudición, esto es, la filiación que, por ejemplo, El acercamiento a Almotasim podría haber reconocido en la inteligencia con que el escritor de "Catherine Necrassoff" y "Bis" bromea, y se divierte con, el lector. Esa paradoja, esa ironía (como quien dice, esa ironía del destino), es uno de los signos más palmarios del tiempo que Mansilla demoró en encontrar su lector.

6 A esta altura resulta bastante obvio recordar que fue la imaginación crítica de David Viñas la que instaló a Mansilla, definitivamente, en el siglo XX. Y no porque se haya ocupado de canonizarlo -su trabajo consistió, por el contrario, en desmontar el desplazamiento neutralizador del que las Causeries y sobre todo la Excursión habían sido objeto por parte de lo que Viñas llamaba el "discurso literario administrativo"15- sino porque esa casi obsesión que lo llevó a volver a su obra una y otra vez a lo largo de cuarenta años le concedió a Mansilla, un siglo después, lo que su escritura siempre reclamó : visibilidad. Solo que el Mansilla del siglo XX que hoy nos sigue llegando de la mano de Viñas y que es, por supuesto, el de los jóvenes kirchneristas de 2011, no es el de Literatura argentina y realidad política, de 1964, ni el de De Sarmiento a Cortázar, de 1971, sino aquel que después de Indios, ejército y fronteras, de 1982, y en los años de la vuelta a la democracia, empezó a releerse en las clases de la universidad pública y a reescribirse en los artículos publicados en los suplementos culturales de mediados de los años 80 . Y la diferencia de perspectiva entre los dos Mansillas de Viñas es, entiendo, importante.

Como lo precisa Claudia Torre cuando repasa estos años, Literatura argentina y realidad política funcionó como un aparato crítico que en las décadas de 1950 y de 1960 discutía con el peronismo y la revista Sur pero que en los años 80, a partir de su reedición en CEDAL y en tándem con las clases que comenzaron en 1986, parecía estar sumamente preparado para recuperar un espacio de debate político y volver a funcionar, aun en las nuevas coyunturas (políticas, teóricas), como un máquina hermenéutica poderosa. ${ }^{16} \mathrm{Sin}$ embargo, el presupuesto de la determinación de clase según el cual Viñas reducía a las Causeries a un "estilo para la oligarquía", limitando sus alcances a las pautas y los gustos de un público de elite y obturando, por consiguiente, la posibilidad de leer en su afán por seducir y entretener la notable predisposición de Mansilla para captar los gustos y la sensibilidad del público moderno del siglo $\mathrm{XIX}^{17}$, ese férreo corset interpretativo que Viñas ajustó entre 1964 y 1971, empezaría a flexibilizarse en la serie de artículos que, en la forma de un montaje de fragmentos recurrentes, publica en Cultura y Nación, La Razón/ Cultura, Crisis, entre 1985 y $1987 .{ }^{18}$ ¿Dónde podrían encontrarse las razones de ese mínimo aunque decisivo giro ? Por un lado, seguramente, en la forma ensayística; podría decirse que la forma misma, fragmentaria, que en esos artículos ponía en escena una capacidad espectacular tanto para sintetizar intuiciones deslumbrantes como para interrumpir y dejar abierto el desarrollo de la argumentación, revirtió sobre la posibilidad de empezar a descomponer el modo comprehensivo y totalizante con el que, después de todo y aunque en clave de crítica ideológica, Literatura argentina y realidad política había vuelto a clausurar la imagen de Mansilla. Pero no solo esto. El prólogo que Horacio González escribe para su reedición en 2003 muestra que probablemente sea en Indios, ejército y 
frontera, escrito en el exilio y publicado por primera vez en 1982, donde pueda situarse el punto de inflexión de esos cuarenta años de lectura. Desde luego, la Excursión forma parte de esta antología de textos que Viñas definió como un "collage problemático" y a partir del cual proponía interpretar a los indios como los desaparecidos de 1879. Pero la sensibilidad crítica de González llama la atención sobre "el corazón estremecedor y problemático" de ese libro, sobre ese núcleo que no sería otro que la "verdadera cicatriz" que para Viñas lleva el nombre Mansilla : el pluralismo móvil de ese "viejo señor criollo proustiano" que enfrenta a Viñas -dice González- con el problema de la "conciencia posible" (“¿era posible que Mansilla fuera más allá ?”) y, más aún, con "el problema vital, al que quizás el conjunto de su obra le debe su impulso angustioso y dramático, [y que] es el de dónde colocar definitivamente a la figura de Mansilla, y acaso dónde colocarse a él mismo". ${ }^{19}$

Me interesa la imagen de esa cicatriz, inscripción en el cuerpo de la herida que produce el encuentro incómodo (¿lacerante ?) con la voz de la élite que seduce. Podría verse en ella el reverso anticipado de la relación novelesca que, en el sentido amplio del término, Viñas entablará desde los años 80 con la obra de Mansilla, y que el gran libro que estaba escribiendo hacia el año 2000, retrospectivamente, nos hace ver mejor. Mansilla entre Rozas y París, ese libro inconcluso que hoy puede consultarse en la Biblioteca Nacional y cuya versión establecida reemplazará definitivamente la deficiente biografía de Enrique Popolizio $^{20}$, se trama sobre una cantidad descomunal de documentos -artículos, partes, recortes periodísticos, informes y cartas : sobre todo cartas- que Viñas fue reuniendo a lo largo de una década para trabajar con ellos de primera mano. En la entrevista que mantuvo con Américo Cristófalo y Hugo Savino en el año 2000 y que recientemente publicó El interpretador, Viñas decía, mientras se entusiasmaba en mostrarlos y comentarlos, que allí, en esos documentos que iban acumulándose en las cajas, estaba "la novela del siglo XIX argentino". ${ }^{21}$ Lo cual quería decir, para Viñas, que eso era una "maravilla", "un novelón", pero también y sobre todo, que "ahí estaba todo". o bien : que eso era una maravilla porque ahí estaba todo. Y es que finalmente, podríamos decir, Viñas encontraba en Mansilla -en los escritos que lo rodeaban, que le pertenecían o que le concernían- el monumento arqueológico balzaciano al que aspiraron siempre las Causeries : todo el XIX argentino, nuestra "gran" novela. Y si esto se hacía posible era porque había dado con una nueva forma de totalidad para leer a su autor fetiche : la clave marxista traducida en clave lukácsiana, la novela como compendio y expresión de una totalidad social.

9 Destaco en el manuscrito dos grandes capítulos, aquellos compuestos a partir de las cartas diarias que Mansilla envía, a distintos destinatarios, entre 1865 y 1870, mientras participó de la Guerra del Paraguay ("IV ${ }^{\circ}$ Momento : Cartas del Paraguay"), y a lo largo de 1869, mientras preparaba la excursión a los ranqueles (" $\mathrm{V}^{\circ}$ Momento: "Frontera. Tácticas y disputas: amagos y ensayo general"). Viñas se interna en ese material, revisa otra vez todos y cada uno de los documentos que habían usado Popolizio o Caillet-Bois, encuentra nuevos, y, como producto de esa incursión, el estilo y el tiempo de su escritura cambian, sensiblemente. ${ }^{22}$ Mientras parafrasea los envíos y respuestas de las cartas -pero prácticamente una a una, día por día, casi renglón por renglón-, el despliegue argumentativo de Viñas, más narrativo que nunca, se demora y se prolonga según un estilo por completo diferente de la forma sintética que caracteriza a las intuiciones fragmentarias de los años $80 .{ }^{23}$ Como si nada quedara sin registrar ; como si todo, cada frase, cada detalle, cada conexión, se volviera relevante; como si el mundo y los 
intervalos de esos días quisieran recomponerse, por completo. Y sin embargo, es precisa la intervención suplementaria de una genuina y productiva relación con lo fragmentario para que ese "todo" comprehensivo funcione, ahora bajo un signo novelesco, en un sentido por completo divergente del que resulta de la interpretación totalizante de Literatura argentina y realidad política. Me estoy refiriendo a esa singular relación entre intuición fragmentaria y captación de la totalidad novelesca que volvió al segundo Mansilla de Viñas un Mansilla más real, más verdadero. Cuando lee "La cabeza de Washington", en el fragmento que titula "Lo indescriptible" (incluido en su artículo "Trece hipótesis"), Viñas observa que el estilo de notación, por cierto singular en el conjunto de las causeries, es fotográfico en el sentido zoliano del término. Pero lo observa -y esto es lo que aquí nos interesa- como si hubiera sabido que mientras Mansilla escribía esta causerie a bordo del Iberia, iba leyendo y traduciendo nada menos que La novela experimental, como si hubiera sabido que a poco de desembarcar en Francia iba a entrevistar y a departir, "de silla a silla", con el mismo Zola en su escritorio. ${ }^{24} Y$ es que en esa espectacular capacidad para captar anticipada y fragmentariamente una verdad se pone en juego otro tipo de totalidad y otra forma de montaje : no el polémico collage que compone la antología del enemigo en Indios, ejército y frontera, sino la conexión novelesca que opera a base de intuiciones y vislumbres. No casualmente es entonces Roberto Arlt quien oficia, y dos veces, como mediador en la relación de Viñas con Mansilla : una vez, cuando en uno de los fragmentos del 80, invoca la figura de Astier para decir que es la traición el único método posible para vincularse con una obra que no se había escrito "para nosotros"; otra vez, cuando en su gran novela del 2000, convierte al fracasado y endeudado buscador de oro en el Erdosain del siglo XIX. ${ }^{25}$ Curioso, e interesante : era precisa la mediación de Arlt, del novelista del siglo XX pero también del escritor antielite, "tironeado entre la humillación y la seducción" ${ }^{26}$, para que la relación novelesca de Viñas con la obra de Mansilla quede fundada.

10 Pero en torno a 1982, mientras volvía de la mano de Viñas con la democracia, la Excursión retornaba además por otras vías. Permeaba también las literaturas de Osvaldo Lamborghini y César Aira a través de dos humores, por lo demás, muy propios de Mansilla : la melancolía y la felicidad.

Así, en las primeras páginas de Las Hijas de Hegel :

En cuanto a literatura, yo prefiero los vislumbres de "La excursión" de ese coronel Mansilla, sus ojos presentados como puntos ciegos de la trama doble, doble trama del relato como cuento y como tal, y como también, como además, trama del hecho histórico que pasa a narrar, pasa y se va : el hecho histórico se pone a narrar ; queda entonces el Desierto como un "misterio", y otro misterio tierra adentro, tierra adentro del primero : ¿por qué los indios se negaron a canjear al doctor Macías, que en nada los beneficiaba, después de haber consentido en ello? El doctor Macías medio loco ya, medio perdida la razón. Hasta hubo una última parada, con los caballos de refresco. Hubo ese último momento de espera. Hubo idas y hubo vueltas. Hubo un triste final inacabado, porque no, a último momento no lo devolvieron a Macías ; nunca sabremos nada de su propia tierra adentro. El desierto..."27

12 Es cierto que la lectura de Lamborghini es incompleta, o fallida, porque el doctor Macías finalmente se suma a la comitiva de regreso. Pero no importa eso ahora. Lo que interesa es su fijación en el momento melancólico del episodio. Si la nostalgia es el signo del "no lugar" de la cautiva y atraviesa, con la fuerza negativa de lo inviable, ese momento clave que es, después del rapto, el regreso ${ }^{28}$, los impedimentos y las negativas que suspenden una y otra vez la salida de Macías de los toldos de Mariano Rozas tienen como marco el mismo viaje de regreso de Mansilla que, además de demorarse a lo largo de los doce 
capítulos finales, es uno de los momentos más inquietantes, e interesantes, de la Excursión . La Junta terminó, los acuerdos fueron ratificados, y, desplazándose ahora con pesada lentitud entre los que vuelven y los que se quedan en el desierto, Mansilla da comienzo a las despedidas y a los preparativos del regreso para terminar preguntándose, con las últimas luces de la tarde, "qué vago y falso presentimiento oprimía angustiosamente [su] pecho"29. Es el momento depresivo del relato, el momento en el que la melancolía da la nota de una atmósfera por completo diferente de aquella que en el comienzo los hacía "galopar en aras de la impaciencia y la curiosidad" ${ }^{30}$. Y es también el momento en que el desierto aparece con toda la fuerza de un espacio fantasmagórico que ahora produce no tanto sueños como imágenes oníricas que el excursionista se trae del viaje como una cauchemar $^{31}$, y en que el mismo se revela -y el episodio de Macías es su mejor cifra- como una encrucijada con un poderoso y desasosegante poder de retención.

13 Es entonces este Mansilla melancólico, que capta en Macías una existencia con "algo de poético, de novelesco y de misterioso", el que resuena en la imaginación de Osvaldo Lamborghini de 1982, en ese relato que con sus fechas -17 de octubre, 16 de setiembre, 1982- pasa por colisiones -revoluciones, golpes, guerras- y encuentra en la "vuelta" la forma de descomponer la totalidad pedagógica de la nación y el progreso de la historia. Si en el relato central, la guerra es aludida en su carácter movilizador y como fuerza de aglutinación nacional ("Las Malvinas en el corazón de Buenos Aires"), es decir, como un lugar al que "se va" y un lugar en el que está representada la nación, en la primera y en la última parte del texto, en cambio, la guerra es el lugar del que se vuelve, malvencido, a ningún lugar. Pero es la vuelta misma la que fractura no solo los espacios de representación nacional sino también la frase y el relato : entre el amague de la frase ("Regresar. Regresar otra vez. Regresar de una buena vez") y la vuelta una y otra vez sobre lo mismo, el regreso de la guerra es lo que en Las Hijas de Hegel, contra la dialéctica hegeliana de la guerra como progreso del relato, no se puede (terminar de) contar. "Regresar. Ex-Malvinas, ex Viet-Nam. Regresar. ...No voy a contar el cuento". La melancolía lamborghiniana interrumpe entonces la escena en que Mansilla lucha, pareciera que vanamente, por sacar a Macías del desierto, para acentuar el carácter desasosegante de ese regreso fallido, o porque ese punto en el que todas las negociaciones están a punto de anularse lo imanta como un fracaso, un triste final inacabado.

Pero en el capítulo previo al episodio de Macías, cuando la gran Junta había finalizado, las paces ya estaban hechas, y el regreso empezaba a anunciarse en las despedidas, Mansilla, cansado, se echa sobre la yerba y se "qued[a] pensativo un rato viendo a los indios desparramarse como moscas en todas direcciones y desaparecer veloces como la felicidad". Las novelas de la pampa de Aira podrían leerse, por cierto, como el espectacular desarrollo imaginario de esta imagen : los indios, veloces como la felicidad. Si Viñas leyó la inclinación al placer de Mansilla como degustación y despilfarro, al mismo tiempo que, desde una moral de izquierda casi victoriana, lo sancionaba, la literatura de Aira, contemporánea de la relectura que se ponía en marcha en los años 80 y mientras reinventaba la pampa argentina, extrajo del desierto de Mansilla las dosis de placer, deseo y extravagancia que la Excursión -como nos lo hizo ver definitivamente Cristina Iglesiaponía en primer plano. ${ }^{32}$

15 No podría decir si Aira efectivamente tiene a Mansilla in mente, pero lo cierto es que los lectores creímos ver el mundo de Mansilla resonando en sus relatos. Así, el vestido rosa, ese objeto minúsculo "sin explicaciones", evocaba de inmediato, en la memoria literaria de quienes lo leíamos, en 1982, el choque del vestidito de brocato con las botas de potro 
que volviéndose ya, en las últimas escenas, Mansilla experimenta en el bautismo de su ahijada como una curiosidad rara, como una incongruencia extraña que le hacía preguntarse una y otra vez: “Qué vestido es ese? ¿de dónde venía? Quién lo había hecho ?" Y la nouvelle de Aira parecía traducir ese "eco inolvidable" que Mansilla decía traerse del desierto para siempre, ese souvenir pesadillesco y fantasmal, a una incongruencia mayor : la desproporción entre las causas nimias y domésticas y los efectos masivos e históricos, lo que es, como sabemos, una de las formas en que Aira desnaturaliza el gran relato histórico del siglo XIX. Del mismo modo, el trastrocamiento de las perspectivas que termina por hacer visible esa singular arquitectura de planos superpuestos y trayectorias envolventes que teñirá de extrañeza las geografías argentinas de Aira, parece un amplio despliegue de esa nube de arena que solo el ojo finísimo y moderno de Mansilla parecía poder captar en el siglo XIX. Dice Mansilla, y lo cito en extensión porque parece adelantar punto por punto la pampa y los efectos ópticos de $L a$ liebre, la novela de la felicidad, escrita en 1987 :

La nube de arena había llamado mi atención antes de empezar el diálogo con Mora, se movía y avanzaba sobre nosotros, se alejaba, giraba hacia el poniente, luego, hacia el naciente, se achicaba, se agrandaba, volvía a achicarse y a agrandarse, se levantaba, descendía, volvía a levantarse y a descender ; a veces tenía una forma, a veces otra, ya era una masa esférica, ya una espiral (...) ; creíamos acercarnos al fenómeno y nos alejábamos, creíamos alejarnos y nos acercábamos, creíamos descubrir visiblemente en su seno objetos y nada veíamos, creíamos juguetes de la óptica la imagen de algo que se movía velozmente de un lado a otro, de arriba abajo, que iba y venía, que de repente se detenía partiendo súbito luego : íbamos a llegar y no llegábamos, porque el terreno se doblaba en médanos abruptos, subíamos, bajábamos, galopábamos, trotábamos con la imaginación sobreexcitada, creyendo llegar en breve a una distancia que despejara la incógnita de nuestra curiosidad; pero nada, la nube se apartaba del camino como huyendo de nosotros, sin cesar sus variadas y caprichosas evoluciones, burlando el ojo experto de los más prácticos, dando lugar a conjeturas sin cuento, a apuestas y disputas infinitas. (Una excursión a los indios ranqueles, capítulo 22)

Pero fue Ema la cautiva, fechada en 1978 y publicada a fines de 1981, leída en su momento como una reescritura y deconstrucción de La cautiva, la que implicaba a Mansilla, antes que a Echeverría, de un modo capital ${ }^{33}$. Conectada con la sensibilidad imaginaria de ese coronel dandy y afrancesado que transfigura a la pampa en un espacio apto, casi ideal, para experimentar el placer de los viajes y que, internándose en los recintos vedados de las tribus ranquelinas, convierte al mundo indígena en un mundo de etiqueta y de artificio, Ema satura a ese universo, tanto el de la frontera como el de los territorios salvajes, con todos los signos de la hipercivilización : las delicias de la más amplia y variada gastronomía, los interiores sobrecargados de mobiliarios y dependencias, los cuerpos indígenas resplandecientes en "torneos de elegancia". Pero además Ema, la cautiva llevaba al extremo la reinvención del desierto que había logrado Excursión : no sólo porque no tiene como objetivo, en absoluto, relativizar a cada paso la dicotomía civilización-barbarie sino porque la disposición hedónica para el ocio, que define toda la atmósfera de la novela apenas se aparta de la órbita de la ley para instalarse en la línea de Pringles, se exhibe como signo de un mundo de refinamiento sobrehumano en el que todo es lujo y excedente. También porque el cultivo artificial de la indiferencia es signo, en el mundo indígena, de un "valor supremo" para mirar de frente a la frivolidad y disponerse al Arte como "fin último de la manía melancólica". Una melancolía, sin embargo, en otra clave. La nostalgia tópica de la cautiva no solo pierde dramatismo en la continua y libre circulación de Ema por el desierto sino que es objeto, a su vez, de una singular 
transfiguración. A través de los mapas, esto es, a través de la localización de un lugar donde instalarse, Ema sale de la melancolía que se había convertido en la atmósfera del desierto ; solo que ese apartamiento no se traduce, como en los hombres y maridos que la rodearon, en certeza de la nada o indiferencia ante la inutilidad, sino en una singularísima prisa de invención. El pasaje a la Acción, esa urgencia por crear un mundo por completo nuevo, es el método con que Aira pone en marcha, con Ema, un centro de reproducción tan artificial como desmesurado e infinito, y la forma en que acomete, con su primera novela de estirpe mansilleana, la fundación mitológica de Coronel Pringles.

Promediando los años 80, entonces, Mansilla vuelve a escena en las clases performáticas de Viñas, en la melancolía nacional de Lamborgini, en la felicidad pampeana de Aira. Y en torno a los años 90 pero sobre todo a partir del año 2000, Mansilla vuelve, por derecho propio, por la vía de los periodistas cronistas, género en el que, después de todo, él confesaba haberse hecho escritor. ${ }^{34}$ Pienso, naturalmente, en María Moreno ; también en Osvaldo Baigorria.

18 Aunque el pretexto de Correrías de un infiel sean las Memorias del Coronel Manuel Baigorria, que vivió entre los ranqueles a mediados del siglo XIX, y aunque el "fifí" de Mansilla solo se invoque cada tanto como una referencia bibliográfica del cronistafilósofo-coronel y etnógrafo amateur, la palabra "correría" en la tapa así como la primera línea que dice "Soy ranquel" y los dos primeros capítulos titulados "El llamado de las erres" y "De chinas y cristianos" traen, de entrada, en el relato de Baigorria, la atmósfera de la Excursión. Si bien su propósito es investigar su probable filiación con el autor de las Memorias, algunos de más relevantes motivos que "empujan" a Mansilla tierra adentro -"la seducción de la barbarie, el "deseo vehemente por internarse entre ranqueles" y la "indecible curiosidad que despertaron en la frontera ciertas relaciones íntimas"- son los que definen, y masivamente, los términos del universo imaginario y erótico que atraen a Baigorria en su viaje al monasterio donde espera encontrar documentos decisivos: primero la curiosidad, pero después la seducción, el deseo, las relaciones íntimas. Y es que la gauchesca erótica de Baigorria que por fin puede -dice- hablar en voz alta, en el siglo XXI, de aquello que nadie en el mundo de los blancos quería escuchar (el goce de la raptada en el desierto), y completar así los puntos suspensivos con los que Mansilla había dejado abierta las insinuaciones de alguno de los refugiados, constituye una exploración sobre el deseo, sobre las liberación de las ataduras de la vida doméstica, sobre la poligamia en clave de multiplicidad de la vida sexual en el mundo de la contracultura. Me interesa aquí sobre todo el modo en que la resonancia de la Excursión es ocasión para otra variante del uso ficcional de la noción de salvajismo, en el sentido en que, de un modo más primario que la operación político-estratégica de Mansilla, las fantasías eróticas de las correrías de este "infiel" evocan ese momento histórico cultural en el que, antes de convertirse en herramienta de crítica intracultural, el salvaje comenzó a transformarse en ideal de humanidad libre para escritores que encontraban en el retorno a los orígenes la vía para poner en crisis la opresiva cultura oficial y expresar sus deseos más íntimos de liberación..$^{35}$ La autoironía, sin embargo, cubre toda la operación. La exploración culmina en una conversión hacia la experiencia amorosa, como efecto de la cual el viajero en diáspora perpetua queda final y gozosamente cautivo del lazo femenino, al mismo tiempo que el ensayo no se exime de una estereotipia machista (el machismo implícito en la idea de "placer de la cautiva") que precisamente la mujer que lo acompaña -la Beatriz interlocutora, pareja y guía- no deja de observar(le) a cada paso. Pero la inteligencia de Baigorria no deja de advertir, además, que, fugitivo de todas las ataduras, no pudo sin 
embargo escapar al lazo de la época. Y en efecto, el salvajismo del infiel se revela entonces tributario del discurso -teórico, político- del presente : es el manifiesto de un "devenir menor e impuro", la opción por "la propia tribu múltiple", "el otro de los otros" como "identidad en adopción". La autoironía con que se confiesa esta sumisión a la época muestra, sin vueltas y sin escrúpulos, la auténtica incomodidad que insiste, necesariamente y todavía hoy, en la incursión al espacio del otro. Podría tener en ese episodio en que el Mansilla militar cae en la trampa del archivo de Mariano Rozas su escena precursora. ${ }^{36}$

19 La devoción de María Moreno por Mansilla, con quien declara haber contraído su segundo matrimonio literario, es, a diferencia de la "debilidad" que Viñas finalmente admite en la entrevista del año 2000, una recurrente declaración de fanatismo. Si esta misma declaración parece, por anticipado, volver redundante nuestras observaciones críticas, intentaremos igualmente ensayar algunas hipótesis sobre los modos en que precisamente la "única dandy mujer que -en palabras de Alberto Giordano- dio hasta ahora el género autobiográfico argentino" ${ }^{17}$ reactualiza al escritor y personaje más moderno del siglo XIX argentino.

Mientras escribe sobre el arte de Alejandro Kuropatwa, Moreno abre un paréntesis para decir que el editor del suplemento donde publica le hace notar lo agobiante que resulta que cite todo el tiempo a Mansilla. Ante lo cual comenta, ahí mismo en el paréntesis : “jes que viene a tan cuento!" ${ }^{38} \mathrm{Y}$ en efecto, no solo el caseur es invocado una y otra vez como un pan precursor de los géneros del siglo XXI -"bloguista avant la letrre", adelantado en "el goce del contacto del chat"-, no solo el cronista de la Excursión es reconocido siempre como un maestro de una serie de "tips" que Moreno, lenguaraz entre el siglo XIX y el XXI, se ocupa de traducir para el ejercicio de la crónica contemporánea, sino que, sea como una referencia para pensar, por ejemplo, en la música de Fogwill, o como un término de comparación para hacer, otro ejemplo, un elogio de la mugre, Moreno trae a Mansilla, cada vez que tiene ocasión, a la conversación. ${ }^{39}$

Pero Mansilla despunta también como la forma misma de la escritura allí donde Moreno se autodefine en el género del periodismo, del ensayo, de la crónica. O exhibe, por ejemplo, su propia lengua al modo en que Mansilla lo hacía con su "erudición a la violeta" en la Excursión : "Aquí furiosamente lacaniana, allá de un demagógico populismo, a veces en vena mística, otras haciendo uso del sermón laico que la lengua política suele llenar de ripios"40. O define sus intervenciones como una articulación entre filosofía menor y capricho al mejor estilo del Diario de mi vida o de las Causeries : "minihipótesis filosóficas, con las que casi siempre estoy ahora en desacuerdo pero que gozan de la impuridad de haber sido enunciadas como los caprichosos parlamentos de un personaje literario" ${ }^{41}$. Por lo demás, así como el primer párrafo de los "Preliminares" a El fin del sexo y otras mentiras puede leerse como una reescritura de ese relato de origen que es la causerie "De cómo el hambre me hizo escritor" -escribir sobre lo que no se sabe o sobre lo que no se conoce como última razón del arte periodístico-, el comienzo del prólogo que titula "Entre Nos" para presentar Vida de vivos declara, con ademán propio de causeur, que ese espacio introductorio destinado a dar cuenta del género entrevista a partir de su propia experiencia es, en realidad, un "pretexto" para entregarse al "impulso de contar [su] propia vida" al mismo tiempo que, según un tópico clásicamente mansilleano, tranquiliza de antemano al lector en relación con su pulsión digresiva. ${ }^{42}$

Ahora bien, si bien es cierto, como dice Giordano, que "Moreno piensa la realidad de las cosas de la cultura argentina con calculada irresponsabilidad teórica, un fervor político 
que sabe conservarse alegre y, sobre todo, o en principio, con voluptuosidad" (Giordano 56), la íntima relación de Moreno con Mansilla no pasaría de coquetería dandy si la cronista no transitara también por la Excursión, según los ajustes que hoy exige la historia política argentina reciente, y según los cuales Moreno, tironeada también entre la atracción y la incomodidad, tiene que vérselas con el coronel como emisario del exterminio. Lo hace en una serie de textos en los que ronda en torno de la(s) memoria(s), del archivo, y de los restos de Mariano Rozas ; más concretamente, en torno del cráneo, esto es, para decirlo según el emblema mismo de Mansilla, la cabeza. Los textos de María Moreno sobre la restitución del cráneo de Mariano Rozas en junio del 2001 podrían titularse, y con los mismos signos de admiración que usó Mansilla en 1878, "¡Esa cabeza ranquel!". ${ }^{33}$

El texto central, "Siempre es difícil volver a casa", es la crónica que Moreno escribe apenas regresada de la excursión de tres días en la que acompañó, desde la ceremonia oficial en el Museo de Ciencias Naturales de La Plata hasta las honras fúnebres definitivas que tuvieron lugar en Leuvucó, la devolución de los restos de Mariano Rozas a la nación ranquel. En principio, y de acuerdo con la ética que la caracteriza, la de abrir grietas en la cultura, la crónica procura sustraerse, cada vez que puede, a las posiciones "políticamente correctas", e ironiza y se divierte con, por ejemplo, el festín para semiólogos que despliega la multiplicidad de signos aptos para la interpretación en este nuevo encuentro de culturas. Pero lo que verdaderamente importa es la exploración de la cronista sobre los alcances y los límites de la incursión. Mientras el fallido emperador de los ranqueles, que desde luego vuelve en el recuerdo, es desplazado al lugar de un fantasma carcajeando detrás de su capa de ceremonia, y mientras el lugar de la flotante y palpitante cabeza toba que obsesionaba a Mansilla en Maracayú es ocupado aquí, y ahora, por las cuencas oculares de Mariano Rozas brillando en la oscuridad, la cronista mide a cada paso, y tácitamente, la profundidad posible de su incursión en la ceremonia. ¿Hasta dónde es posible adentrarse ? ¿Qué y hasta dónde es legítimo mirar y cuál tendría que ser la ética de ese registro ? En este sentido, como el coronel en 1870 en su camino a Leuvucó, María Moreno oficia de escucha en los fogones que se arman espontáneamente en Victorica, y las autobiografías orales que allí atestigua siguen enunciándose con el tono del lamento (aunque no se trata ya, desde luego, del testimonio de las víctimas de la justicia letrada que buscaban refugio en el desierto sino del de sus descendientes discriminados en los pueblos o ciudades del siglo XX). Pero la cronista realiza las entrevistas a esos nuevos marginados del cuerpo nacional como dando un paso hacia atrás y declinando todo protagonismo. Y es esta actitud corporal -la única, por lo demás, acorde con la ética testimonial que exige "la viabilidad del movimiento indígena en el siglo XXI"- la que convierte a la crónica y a los desplazamientos que registra en un incómodo ejercicio de exploración sobre el lugar del testigo. La autoironía, sin embargo, retorna, porque de nada huye más María Moreno que de la seguridad que suponen tanto "los privilegios de pertenecer a la cultura" como de las posiciones irreprochables cristalizadas. El movimiento es, entonces, doble. Por un lado, la cabeza vuelve, fantasmal, en 2002, en un artículo en el que Moreno recorre una serie de "cabezas" como si recorriera un inventario de los lugares o pretextos para actos de (in)justicia (condena frenológica, discriminación racial, crimen mafioso, despojo y restitución) reeditando los devaneos de Mansilla en su escritorio de Maracuyá : ¿cómo y qué leer en una cabeza separada del cuerpo ${ }^{{ }^{44}}$ Por el otro, cuando vuelve a pensar en Mariano Rozas para subrayar, una vez más, la escena del archivo, Moreno recuerda cómo lloró en la ceremonia de restitución en Leuvucó, pero también cómo lloró en la muestra de "Arte Pampa" del Bicentenario ante el poncho que el 
cacique le había regalado al coronel. Y lo hace -y todo el interés está aquí- sin dejar de confesar la frivolidad de ese llanto de tinte culturoso. Se lee en la primera entrada de Subrayados ("La escena del archivo") :

"Llorando vi [los] cabezales y [los] estribos [de Panguitruz Guor] en la muestra "Las pampas : arte y cultura en el siglo XIX" en la galería Proa, quinientas piezas de platería, ponchos y mates fruto de la donación, de la compra y la venta, pero sobre todo del saqueo. [...] Llorando vi el entierro de la calavera de Pantaguitruz Guor en Leuvucó, rodeado de una comunidad de empleados públicos, de porteras y maestras a las que el historiador José Depetris les restituyó con sus investigaciones su sangre azul ranquelina [...] Demás está decir que yo no lloraba de progre sino porque rara vez se puede asistir al entierro de un personaje literario."

La transmutación de la cicatriz de Viñas en el lloriqueo frívolo de Moreno, de una expresión corporal en otra, podría estar señalando la parábola que dibujan los diversos usos, críticos y políticos, que desde el retorno a la democracia la intelectualidad argentina hace de los imaginarios asociados con Mansilla. María Moreno, que en 2004 organiza en el Centro Cultural Ricardo Rojas un "Parlamento Mansilla" para que escritores, performers y profesores se reconozcan, entre el juego y el ejercicio de la crítica, en el placer de la opción estética, trae a Mansilla a la conversación como un guiño de un signo por completo distinto al de los sobreentendidos de David Viñas. No lo hace, sin embargo, como tampoco lo hacía Viñas, para acompañar un proceso político determinado. El Estado no es el lugar en que se reconoce su discurso. Y puede usar entonces, crítica y políticamente, a Mansilla, sin mayores escrúpulos ni responsabilidades. Lo hace con la libertad que le da una ética comprometida con las heridas y mancillas de su presente, aunque no adscriba su escritura a una función estatal.

\section{NOTAS}

1. Los números son los siguientes : Mancilla. La época. Año 1, $\mathrm{N}^{\circ} 1$, noviembre 2011 ; Mancilla. Año 2, $\mathrm{N}^{\circ}$ 2, abril 2012; Mancilla. Año 2, $\mathrm{N}^{\circ}$ 3, agosto 2012. Mancilla. Año 2, $\mathrm{N}^{\circ} 4$, diciembre 2012 ; Mancilla. Año 2, $\mathrm{N}^{\circ}$ 5, junio 2013 ; Mancilla. Año 3, $\mathrm{N}^{\circ}$ 6, noviembre 2013.

2. Epígrafe del dossier "Textos y texturas del kirchnerismo" en Mancilla. La época 01, p. 4.

3. Así lo define Gisela Catanzaro en la entrevista que le hacen, para el primer número, Minici, La xagueborde, Maidana y Caramés. Mancilla 01, p. 35.

4. Epígrafe del dossier "Textos y texturas del kirchnerismo" en Mancilla. La época 01, p. 4.

5. Las elecciones presidenciales, en las que Cristina Fernández renovó su mandato con el $54 \%$ de los votos, tuvieron lugar el 23 de octubre de 2011. El Instituto Manuel Dorrego se creó el decreto 1880/2011 el 17 de noviembre de 2011. La Batalla de La Vuelta de Obligado, en la que la Confederación Argentina enfrentó a la escuadra anglo-francesa, tuvo lugar el 20 de noviembre de 1845 y el encargado de la defensa del territorio nacional fue el general Lucio N. Mansilla, padre de Lucio V.

6. Según se definen en su página institucional, "Carta Abierta es un espacio no partidario ni confesional conformado por personas de la cultura, la educación, el periodismo, las ciencias, el cine, las artes, la poesía y la literatura, entre otras disciplinas [que] surgió en marzo de 2008, en defensa del gobierno democrático amenazado por el conflicto suscitado por las patronales 
agropecuarias, y distinguiéndose siempre por la preservación de la libertad de crítica". Además de Horacio González y María Pía López, dos miembros destacados de Carta Abierta, tienen un espacio importante en la revista escritores y críticos próximos a estas posiciones como Alejandro Rubio, Damián Selci, Sergio Raimondi.

7. María Pía López: "Lucio V. (Anotaciones sobre la frontera)", “Epílogo" en Mancilla 01, pp. 76-80.

8. Lucio V. Mansilla : "Un hombre comido por las moscas" en Entre-nos. Causeries del jueves. Buenos Aires, Librería Hachette : 1963

9. Ricardo Rojas, Los modernos, tomo II Historia de la literatura argentina, Buenos Aires, Librería La Facultad, 1925.

10. Cf. David Viñas, Literatura argentina y realidad política, Buenos Aires, Centro Editor de América Latina, 1982, p. 192, y Ezequiel Martínez Estrada: Sarmiento, Rosario, Beatriz Viterbo Editora, 2001, p. 111.

11. El idioma de los argentinos. Buenos Aires, Seix Barral, 1994, p. 145.

12. Cf. Ivonne Bordelois: "El idioma de los argentinos. Cultura y discriminación" en http:// www.lehman.cuny.edu/ciberletras/v06/bordelois.html

13. Me refiero al ensayo "La supersticiosa ética del lector" (Obras Completas, Buenos Aires, Emecé, 1974, p. 203) y el relato "Historia del guerrero y la cautiva" (Obras completas, ed. cit., pp. 558-559).

14. En relación con la épica del individuo contra el Estado, remito a mi trabajo: "Breves intervenciones con Sarmiento. A propósito de "Historias de Jinetes"” en Jorge Luis Borges : políticas de la literatura. Juan Pablo Dabove, editor. Instituto Internacional de Literatura Iberoamericana, 2008, p. 84.

15. David Viñas: Indios, ejército y frontera. Buenos Aires, Santiago Arcos Editor, 2003, p. 160. (Primera edición : México, Siglo XXI, 1982)

16. Claudia Torre: "Más allá de la letra. Literatura argentina y realidad política en la década de 1980". Prismas. Revista de historia intelectual, № 14, 2010, pp. 177-181.

17. Desarrollé esta hipótesis en "Lucio V. Mansilla : cuestiones de método" en Historia crítica de la literatura argentina, director : Noé Jitrik. Volumen $3:$ El brote de los géneros, dirigido por Alejandra Laera. Buenos Aires, Emecé Editores, 2010, pp. 199-232

18. Los artículos son: "David Viñas. Las miserias secretas", entrevista de Carlos Dámaso Martínez, en La Razón/Cultura, 10 de noviembre de 1985 ; David Viñas : “Trece hipótesis” en La Razón, 16 de febrero de 1986 ; "De duelos, chinas y memorias" en Clarín. Cultura y Nación, 22 de mayo de 1986; . “Dandys, heterodoxias y traidores” en Crisis, № 53, abril 1987. "Mansilla, el insolente" se publicó en Radar libros el 10 de enero de 1999.

19. Horacio González : "Prólogo" a David Viñas : Indios, ejército y frontera, ed. cit., pp. 10-11.

20. El manuscrito puede consultarse en la sección Archivos y Colecciones Particulares de la Biblioteca Nacional. Será publicado por la editorial Santiago Arcos, en 2015, como el sexto volumen de la "Colección David Viñas" que dirige Américo Cristófalo para la editorial, con trabajo preliminar y trabajo de archivo de Andrés Tronquoy. Un adelanto del libro, el capítulo "Mansilla entre Darío y Proust", y el artículo de Andrés Tronquoy sobre el trabajo de edición, "Un Viñas inédito", pueden leerse en La Biblioteca, N 12, Primavera 2012, pp. 68-81.

21. Américo Cristófalo y Hugo Savino : Entrevista a David Viñas "Mansilla : una novela argentina del siglo XIX" [2000] Publicada en El Interpretador $\mathrm{n}^{\circ} 37 / 38$, 2011; http:// www.elinterpretador.net/

22. Para una lectura del Mansilla de Viñas como un "efecto de archivo" y como la "versión perfecta y desbocada del libro que se continuó en forma ininterrumpida durante cinco décadas", ver el excelente artículo de Juan Pablo Canala : "Mansilla y Viñas : desvelos de archivo" en La Biblioteca, $\mathrm{N}^{\circ} 12$, primavera 2012, pp. 82-91.

23. Un ejemplo de la minuciosa reconstrucción narrativa de las cartas que puede leerse en " $\mathrm{V}^{\circ}$ Momento: "Frontera. Tácticas y disputas : amagos y ensayo general" : "El 13 de marzo del 69, 
Arredondo le 'manifiesta el deseo' de que 'a mediados de abril esté sobre el Río 50'. Mansilla contesta: 'Estoy pronto a moverme por mañana mismo'. Sí. 'Si me manda caballos'. No hay respuesta. Además ‘se asegura' que el próximo invierno será 'crudísimo'...”.

24. Viñas lee "La cabeza de Washington" en la versión incluida en los tomos de Entre-nos. Causeries del jueves. Desconocía la publicación del artículo en La Tribuna Nacional, el 10 de abril de 1881, así como el texto "Sobre cuberta", publicado en el mismo diario el 29 de marzo de 1881, donde Mansilla traduce un fragmento de La novela experimental que va leyendo mientras se traslada a Europa en el Iberia. Este material fue dado a conocer en Lucio V. Mansilla : El excursionista del planeta. Escritos de viaje. Selección y prólogo de Sandra Contreras. Buenos Aires, Fondo de Cultura Económica, 2012.

25. Me refiero al apartado titulado "Arlt, Mansilla ; traidores y heterodoxias" incluido en David Viñas: "Dandys. Heterodoxias y Traidores", art. cit., y al apartado "Oro y literatura" en el capítulo provisoriamente titulado "VII ${ }^{\circ}$ Movimiento: Peste y oro, Avellaneda y el Chaco" del manuscrito Mansilla entre Rozas y París que se encuentra en la Biblioteca Nacional.

26. "El escritor vacilante : Arlt, Boedo y Discépólo" en De Sarmiento a Cortázar, Buenos Aires, Siglo Veinte, 1974 , p. 63 y p. 67.

27. Osvaldo Lamborghini : Novelas y cuentos, Barcelona, Ediciones del Serbal, 1988, p. 144.

28. Cf. Cristina Iglesia : "La mujer cautiva : cuerpo, mito y frontera" en La violencia del azar. Ensayo sobre literatura argentina. Buenos Aires, Fondo de Cultura Económica, 2002.

29. Una excursión a los indios ranqueles, capítulo 68. Buenos Aires, Centro Editor de América Latina, 1980, Tomo II, p. 189.

30. Una excursión a los indios ranqueles, capítulo 20. Ed. cit., Tomo I, p. 129.

31. Cf. el episodio del vestido en el capítulo 58.

32. Cf. Cristina Iglesia "Mejor se duerme en la pampa. Deseo y naturaleza" en La violencia del azar, ed. cit.

33. Desarrollé estas hipótesis en "Prólogo" a Ema, la cautiva, de César Aira. Buenos Aires, Eudeba, colección de Clásicos argentinos dirigida por Sylvia Saítta y José Luis de Diego, 2011.

34. Me refiero a la causerie "De cómo el hambre me hizo escritor", incluida en Entre-nos. Causeries del Jueves.

35. Cf. Hayden White: "The forms of wildness. Archeology of an idea" en Tropics of discourse. Essays in Cultural Criticism. Baltimore, The John Hopkins University Press, 1978.

36. Me refiero al capítulo 40 de la Excursión, al episodio en que Mariano Rosas le muestra el archivo de artículos de La Tribuna en que se habla de la intención del Estado de hacer pasar un ferrocarril por las tierras ranqueles. En relación con la lectura de la novela de Baigorria, cito aquí el comentario de Javier Gasparri a la lectura de parte de este trabajo en las III Jornadas internas del Centro de Estudio en Literatura Argentina que tuvieron lugar e la Facultad de Humanidades y Artes de Rosario, el 18-19 de noviembre de 201 : "Correrías de un infiel, por supuesto, "completa los puntos suspensivos que Mansilla había insinuado”, en relación con los placeres en el desierto, pero además lo lleva más lejos en el gesto indagador : la novela de Baigorria comienza allí donde Mansilla se detiene : en el espacio de la orgía y la poligamia. Claro está que Baigorria escribe su relato con el siglo XX y sus propias vivencias tras de sí, por eso la imaginación del desierto con la que nos encontramos está procesada por las corrientes contraculturales y libertarias (lo que vuelve, entonces, sería menos un desierto con Mansilla a caballo que una road movie, o un Mansilla-beatnik, o procesado con Kerouac). A partir de allí se comprende la alusión al "fifí" de Mansilla en la novela : como el reclamo de un libertario hacia un liberal. Por eso, el imaginario que permea la novela de Baigorria se hace presente a partir de lo que él mismo entenderá como amor libre, para lo cual "se necesitan dosis parejas de inocencia y experiencia" (que no deben confundirse con ingenuidad y cinismo, respectivamente), y cuyo principio no está dado por la mera posibilidad de tener múltiples relaciones sexuales sino por la de "amar a varias personas al mismo tiempo" (Baigorria 2006: 7 y 11). En este sentido, Baigorria se muestra atento a las 
complejidades, tensiones y fragilidades de "la conflictiva pareja de Eros y Anarquía". De lo que se desprende que, en la novela, el salvaje funciona menos como un "ideal" de humanidad libre para poner en crisis la cultura oficial opresiva, que como una auténtica transfiguración imaginaria corporalizada, es decir, provista de cuerpos (deseantes y deseables) en uso y de carne en movimiento. Y al mismo tiempo, sí hay algo de crítica intracultural, que ya no será la torsión civilización-barbarie como Mansilla, sino la crítica a los estilos de vida (monogámicos, conservadores, institucionalizados, etc.). Finalmente, Mansilla vuelve en Baigorria en ciertas operaciones de escritura : no tanto en el tono (claramente autoirónico en Baigorria, que puede deberse a cierta recuperación de la línea libertina), sino en el modo de hacer ficción : de la propia vida al relato (autoficción), al ensayo y a la conversación digresiva con el lector." Referencia : Baigorria, Osvaldo : El amor libre. Eros y Anarquía. Buenos Aires, Anarres-Utopía Libertaria, 2006.

37. Alberto Giordano: "María Moreno : la entrada en la cultura" en El giro autobiográfico en la literatura argentina actual. Buenos Aires, Mansalva, 2008, p. 57.

38. En "Superficies de placer", Radar, 9 de febrero de 2003.

39. Remito al "Prólogo" a Una excursión a los indios ranqueles. Buenos Aires, Ediciones Terramar, 2010, y a los artículos publicados en Radar: "Música", 29 de agosto de 2010 ; "Elogio de la mugre", 11 de agosto de 2002.

40. "Preliminares" en El fin del sexo y otras mentiras. Buenos Aires, Editorial Sudamericana, 2002, p. 7.

41. "Locuelas" en A tontas y a locas. Buenos Aires, Editorial Sudamericana, 2001, p. 10.

42. "Entre nos (apuntes para una teoría de la entrevista)" en Vida de vivos. Conversaciones incidentales y retratos sin retocar. Buenos Aires, Editorial Sudamericana, 2005, p. 7.

43. Los textos son : "Siempre es difícil volver a casa", Radar, $1^{\circ}$ de julio de 2001 ; "Cabezas", Radar libros, 29 de setiembre de 2002 ; "La escena del archivo" en Subrayados. Leer hasta que la muerte nos separe. Buenos Aires, Mardulce, 2013. Mansilla incluye “¡Esa cabeza toba!” en los volúmenes de Entre-nos, pero había escrito y publicado el artículo en 1878, durante su estadía en las Minas de Amambay y Maracayú, en Paraguay.

44. El artículo, publicado el 29 de setiembre de 2002, se titula "Cabezas" y enseguida es incluido como uno de los apartados del capítulo "Postales" publicado en El fin del sexo y otras mentiras en noviembre de 2002 .

\section{RESÚMENES}

Este artículo se ocupa de trazar el mapa de interpretaciones, reescrituras y usos de los que es objeto la literatura y el nombre de Lucio V. Mansilla desde la segunda mitad del siglo XX hasta el presente : desde la indiferencia de Borges hasta la fascinación de María Moreno, pasando por la crucial obsesión de David Viñas, las escenas de Osvaldo Lamborgnini y de César Aira, el relato de Osvaldo Baigorria y la intervención política de los jóvenes kirchneristas de la revista Mancilla. El objetivo del trabajo es dar cuenta de la vigencia de Mansilla como escritor del siglo XX a través de sus diversos retornos a lo largo de las últimas cinco décadas en la crítica y literatura argentinas.

L'objectif de cet article est de dessiner la carte des interprétations, réécritures et usages dont ont fait l'objet la littérature et le nom de Lucio V. Mansilla depuis la seconde moitié du XXe siècle et jusqu'à la date d'aujourd'hui : de l'indifférence chez Borges à la fascination chez María Moreno, en passant par l'obsession récurrente chez David Viñas, les scènes d'Osvaldo Lamborgnini et de 
César Aira, le récit d'Osvaldo Baigorria et l'intervention politique des jeunes partisan des Kirchner de la revue Mancilla. Il s'agit de rendre compte de la persistance de Mansilla comme écrivain du XXe siècle à travers ses différents retours au cours des cinq dernières décennies dans la critique et la littérature argentines.

The main purpose of this paper is to draw the map of interpretations, rewritings and uses of Lucio V. Mansilla's literature and Lucio V. Mansilla's name from the second half of the 19th century to the present. From Borges' indifference to María Moreno's fascination, a wide range of positions can be observed: David Viñas' obsession, Osvaldo Lamborgnini's and César Aira's scenes, Osvaldo Baigorria' narrative and the political action of young Kirchner supporters writing in Mancilla magazine. The aim of this article is to report on the importance of Mansilla as a writer of the 20th century, studying his presence in argentine criticism and literature in the last five decades.

\section{ÍNDICE}

Mots-clés: Lucio V. Mansilla, réécritures, lectures, XXe siècle

Palabras claves: Lucio V. Mansilla, reescrituras, lecturas, siglo XX

Keywords: Lucio V. Mansilla, rewritings, readings, 20th century

\section{AUTOR}

SANDRA CONTRERAS

CONICET-UNR 